\title{
TRATAMENTOS SILVICULTURAIS EM MUDAS DE Allophylus edulis (A. St.-Hil., Cambess. \& A. Juss.) Radlk. PARA ARBORIZAÇÃO DE RUAS
}

\author{
Daniela Biondi*, Luciana Leal**, Jaime Luiz Cobalchini*** \\ *Enga . Florestal, Dra ., Depto. de Ciências Florestais, UFPR - dbondi@ufpr.br \\ **Enga . Florestal, Mestranda em Engenharia Florestal, UFPR - luciana paisagem@yahoo.com.br \\ ***Eng. Florestal, Depto. de Produção Vegetal, Prefeitura Municipal de Curitiba - hortobarreirinha@smma.curitiba.pr.gov.br
}

Recebido para publicação: 13/09/2006 - Aceito para publicação: 31/05/2007

\begin{abstract}
Resumo
A arborização de ruas das cidades brasileiras geralmente é composta por espécies exóticas, principalmente pela falta de conhecimentos sobre o comportamento das espécies nativas no meio urbano e a produção de mudas. Este trabalho teve como objetivo avaliar a produção de mudas de Allophylus edulis (A. St.-Hil., Cambess. \& A. Juss.) Radlk. com a aplicação de tratamentos silviculturais, visando obter mudas com características adequadas para a arborização de rua. Foram aplicados os seguintes tratamentos nas mudas: $\mathrm{T} 0=$ testemunha, sem aplicação de poda; $\mathrm{T} 1=$ poda no primeiro mês (instalação do experimento); $\mathrm{T} 2$ = poda depois de três meses da instalação do experimento; $\mathrm{T} 3$ = poda depois seis meses; e $\mathrm{T} 4$ = poda depois de nove meses. As variáveis analisadas foram: incremento em altura total e diâmetro de colo, altura de bifurcação e número de rebrotas. A aplicação de podas proporcionou maior incremento em altura, mas não alterou o incremento em diâmetro. Observou-se menor crescimento nas avaliações correspondentes ao período outono/inverno. Após as podas, observou-se a formação de brotações laterais. Não houve diferença entre a realização de podas sucessivas e de uma única poda. Recomendam-se, para fins práticos, podas sucessivas a cada 9 meses em mudas de Allophylus edulis.
\end{abstract}

Palavras-chave: Poda; brotações; altura de bifurcação.

\begin{abstract}
Silvicultural treatments in seedlings of Allophylus edulis (A. St.-Hil., Cambess. \& A. Juss.) Radlk. for urban street trees. The Brazilian urban forestry is generally consisted of exotic species mainly due to the lack of knowledge about native species in urban areas and their seedlings production. The aim of this work was to evaluate the Allophylus edulis' seedling production applying silvicultural treatments to obtain seedlings with suitable features for urban forestry. The following treatments were applied on the seedlings: $\mathrm{TO}=$ witness with no pruning, $\mathrm{T} 1=$ pruning on the first month (experiment settling), $\mathrm{T} 2=$ pruning after three months of experiment settling, $\mathrm{T} 3=$ pruning after six months and $\mathrm{T} 4=$ pruning after nine months. The analyzed variables were: total height growth and collar diameter, fork height and recoppicing number. The pruning caused a greater growth in height but it did not alter the diameter growth. The evaluations done in fall and winter showed a lesser growth. After the pruning, lateral coppicing was observed. There was no difference between the successive pruning and the only one pruning. It is suggested, for practical reasons, successive pruning each nine months for Allophylus edulis.
\end{abstract}

Keywords: Pruning; shoots; fork height.

\section{INTRODUÇÃO}

Para que a arborização de ruas cumpra com seus benefícios estéticos e funcionais, é necessário que os esforços não sejam concentrados somente no plantio e na manutenção, mas principalmente na produção de mudas. A qualidade das mudas na arborização de ruas irá refletir no melhor desenvolvimento das espécies e em menores intervenções nas futuras árvores em relação ao meio, principalmente quanto ao uso indiscriminado de podas. 
Uma muda formada adequadamente para a arborização de ruas precisa apresentar as seguintes características: tamanho mínimo de 2,00 m de altura; altura da primeira bifurcação não inferior a 1,80 m; tronco retilíneo e perpendicular ao nível do solo; diâmetro mínimo à altura do peito superior a $3 \mathrm{~cm}$; copa formada por no mínimo três ramos alternados; ramificação e folhagem reduzidas na época de plantio; rusticidade para tolerar as condições adversas do meio urbano; bom estado nutricional e fitossanitário; sistema radicular bem desenvolvido; volume de torrão adequado isento de plantas daninhas e adequadamente embalado (GONÇALVES et al., 2004; BIONDI; ALTHAUS, 2005).

Segundo Santiago (1980), as mudas de tamanho pequeno (abaixo de 1,00 m) não são adequadas, porque pode ocorrer excessiva brotação lateral, obrigando a podas de condução, e dificilmente a copa irá se formar na altura conveniente, enquanto que as mudas grandes (acima de 1,00 m) apresentam a vantagem de serem mais resistentes à predação, com maior capacidade de brotação e copa formada na altura conveniente.

A formação de mudas inadequadas para as calçadas poderá corresponder a problemas futuros, não só com a estrutura urbana, mas com as próprias árvores urbanas. Os problemas mais comuns encontrados após o plantio nas ruas são: baixa percentagem de sobrevivência das mudas, devido ao tamanho pequeno e facilidade de depredação por vandalismo, e malformação das mudas pela falta de tratos culturais necessários no viveiro. O custo das mudas para arborização de ruas é alto, principalmente devido à sua permanência no viveiro por um longo período (acima de 2 anos). Porém, todo esse ônus pode ser compensado com o planejamento do local adequado e a produção de mudas com qualidade (BIONDI; ALTHAUS, 2005).

No viveiro, as mudas devem receber os tratamentos silviculturais relacionados com a técnica de produção na qual se procura formar mudas com padrões ideais para arborização de ruas (BIONDI, 1987). Depois que as mudas esgotam o crescimento nos recipientes menores, aproximadamente um ano após a semeadura, elas devem ser transplantadas para recipientes maiores ou para o viveiro de espera. Nessa fase, as mudas deverão ser conduzidas corretamente, aplicando-se tratos culturais específicos, como o tutoramento e as podas de condução e formação (PAIVA; GONÇALVES, 2001).

A poda, como tratamento na condução da muda no viveiro de espera, consiste na remoção de partes da planta, que geralmente são brotações e galhos, mas também podem ser raízes e até mesmo flores e frutos. Em mudas, as podas fazem parte dos tratamentos aplicados para assegurar plantas estruturalmente fortes e com menor necessidade de podas corretivas quando adultas (HARRIS, 1992).

$\mathrm{Na}$ produção de mudas, a poda de condução livra o tronco das ramificações indesejadas ou brotações laterais, proporcionando à muda um aspecto de árvore (BIONDI; ALTHAUS, 2005). Essa poda permite que o crescimento ocorra apenas pela gema terminal, com a moldagem da muda para que ela atinja a altura mínima desejada para início da formação da copa. Já a poda de formação tem por objetivo adequar e definir a forma e até mesmo o porte definitivo da árvore ao espaço disponível para o seu crescimento (CEMIG, 2000). Essa poda é aplicada para direcionar o desenvolvimento da copa contra a tendência natural do modelo arquitetônico da espécie, compatibilizando assim a árvore com os espaços e equipamentos urbanos (SEITZ, 2003).

As podas de condução e formação são uma das formas mais eficientes de adequar as mudas para plantio nas ruas, onde o espaço é bastante restrito. Esse requisito é imprescindível, pois evita danos à árvore e aos pedestres que transitam pelas ruas (BIONDI; MEUNIER, 1987). A correta execução da poda de formação pode determinar facilidades futuras em podas preventivas e diminuição dos conflitos entre árvores e redes aéreas (CEMIG, 2000).

A maioria das espécies só consegue ter um fuste único e reto, na altura desejada, em função desses tratamentos e com a ajuda do tutoramento (DOMINGUES, 1987; PAIVA; GONÇALVES, 2001). Algumas espécies têm tendência ao crescimento arbustivo, ou seja, com formação de mais de um ramo desde a base. Nesse caso, o ramo mais bem formado deve ser escolhido como principal e os demais devem ser eliminados (DOMINGUES, 1987).

Nas cidades brasileiras, a arborização de ruas é composta principalmente por espécies exóticas. Um dos maiores impedimentos para o uso de espécies nativas é a falta de conhecimento sobre o comportamento dessas espécies no meio urbano e a produção de mudas.

Allophylus edulis (A. St.-Hil., Cambess. \& A. Juss.) Radlk. (Sapindaceae) é uma espécie nativa do Brasil e é bastante ornamental, podendo ser empregada com sucesso na arborização de ruas e praças. Essa espécie, algumas vezes, pode apresentar tronco tortuoso (REITZ, 1980) ou curto (BACKES; 
IRGANG, 2004), necessitando de tratos silviculturais para a obtenção de mudas com características adequadas.

Para conhecer o comportamento de Allophylus edulis em viveiro de espera, este trabalho teve como objetivo avaliar a produção de mudas com a aplicação de tratamentos silviculturais, visando formar mudas com características adequadas para a arborização de ruas. Especificamente, foram analisadas a quantidade, a freqüência e a época ideal para a realização de tratamentos silviculturais (poda), a fim de formar uma muda com o tronco livre de ramificações.

\section{MATERIAL E MÉTODOS}

\section{Características da espécie}

A espécie Allophylus edulis (A. St.-Hil., Cambess. \& A. Juss.) Radlk., pertencente à família Sapindaceae, é conhecida vulgarmente como vacum, vacunzeiro, chal-chal, baga-de-morcego, fruta-depombo e murta-vermelha, entre outras designações (REITZ, 1980; LORENZI, 1992; BACKES; IRGANG, 2004).

O gênero Allophylus vem do grego állos (de outro) e phylus (nação), referindo-se a uma situação geográfica, pois o material da descrição original era procedente do Ceilão (atual Sri Lanka). Já o nome específico edulis (do latim) significa comestível, sendo seus frutos muito apreciados pelo homem e pelos animais silvestres (REITZ, 1980; MARCHIORI, 1995).

No Brasil é encontrada no Amazonas, Ceará, Bahia, Mato Grosso, Minas Gerais, Rio de Janeiro, São Paulo, Paraná, Santa Catarina e Rio Grande do Sul. Também nas Guianas, Bolívia, Paraguai, Uruguai e Argentina (REITZ, 1980; BACKES; IRGANG, 2004). Ocorre na Floresta Ombrófila Mista Montana e Aluvial (RODERJAN et al., 2002), tanto em locais com luminosidade intensa como à sombra, predominando nos estratos médio e interior da floresta (SANCHONETE, 1989).

A espécie é facilmente reconhecida por suas folhas compostas por três folíolos serrados, com intensa floração branca e especialmente por seus frutos vermelhos, que lhe conferem um contraste vivo sobre sua copa densa verde-escura (BACKES; IRGANG, 2004). Planta semicaducifólia, possui copa simpodial e arredondada (GIMENEZ; MOGLIA, 2003), fechada, com folhagem densa e ramificação dicotômica abundante (REITZ, 1980).

Possui porte pequeno, de até $10 \mathrm{~m}$ de altura, com fuste de até $45 \mathrm{~cm}$ de diâmetro (BACKES; IRGANG, 2004). É citada como arvoreta ou árvore de 5-20 m de altura e 15-30 cm de diâmetro na altura do peito por Reitz (1980) e altura de 6 a 10 m, com tronco de 20-30 cm de diâmetro por Lorenzi (1992), podendo atingir $20 \mathrm{~m}$ de altura e $30 \mathrm{~cm}$ de diâmetro segundo Carvalho et al. (2004). A taxa de crescimento é média (GIMENEZ; MOGLIA, 2003).

O florescimento ocorre durante os meses de setembro a novembro e a frutificação em novembro a dezembro (LORENZI, 1992). Anualmente, produz grande quantidade de frutos, porém, na mesma árvore são encontrados frutos em diferentes estágios de maturação no período de dispersão de sementes (MEDEIROS; ABREU, 2003). Na produção de mudas, a emergência ocorre em 20-30 dias e a germinação geralmente é superior a $80 \%$. As mudas ficam prontas para o plantio no campo em menos de seis meses. O desenvolvimento das plantas no local definitivo geralmente é rápido (LORENZI, 1992). Aos 12 meses de idade pode alcançar de 30 a $50 \mathrm{~cm}$ de altura (SANCHONETE, 1989).

Por ser bastante ornamental, essa espécie pode ser empregada com sucesso na arborização de ruas e praças (LORENZI, 1992; CARVALHO et al., 2004), além de ser considerada como árvore ideal para plantio em pequenos espaços (BACKES; IRGANG, 2004). É uma planta rústica, que vem sendo utilizada em praças, parques e jardins do município de Porto Alegre, demonstrando boa resistência às condições urbanas. A natureza do sistema radicial, a adaptabilidade tanto à luz quanto à sombra e o médio porte dessa espécie permitem que se recomende o seu plantio em calçadas e canteiros centrais de avenidas, inclusive onde há rede elétrica e/ou telefônica (SANCHONETE, 1989).

\section{Procedimentos metodológicos}

Foram obtidas mudas de Allophylus edulis no Horto Municipal da Barreirinha da Prefeitura Municipal de Curitiba (PR), com idade de 3 anos. Essas mudas foram transplantadas para vasos plásticos (volume $8 \mathrm{~L}$ ) com substrato composto por mistura de três partes de composto-orgânico (horizonte A), uma parte de mistura triturada produzida pelo Horto Municipal a partir de restos de poda da arborização, 
$200 \mathrm{~g}$ de adubo NPK 10-10-10 e $100 \mathrm{~g}$ de calcário. Anualmente, foram aplicadas $30 \mathrm{~g}$ de adubação NK 10-10 em cada vaso. Todas as mudas foram tutoradas com estacas de bambu para corrigir o fuste devido à ação dos ventos. As mudas foram orientadas no viveiro de espera no sentido nordeste (NE).

O experimento, iniciado em fevereiro de 2004 e conduzido por 24 meses, foi desenvolvido no viveiro de espera do Laboratório de Paisagismo do curso de Engenharia Florestal da Universidade Federal do Paraná, na cidade de Curitiba (PR).

O delineamento experimental utilizado foi o inteiramente casualizado, com cinco tratamentos e oito repetições. O trato silvicultural aplicado foi a poda de condução, isto é, a retirada de gemas, ramos e/ou galhos localizados a uma altura preestabelecida nas avaliações trimestrais. Foram realizados os seguintes tratamentos: $\mathrm{T} 0=$ testemunha, sem aplicação de poda; $\mathrm{T} 1$ = poda no primeiro mês (na instalação do experimento); $\mathrm{T} 2$ = poda depois de três meses da instalação do experimento; $\mathrm{T} 3$ = poda depois de seis meses da instalação do experimento; e T4 = poda depois de nove meses da instalação do experimento. Os tratamentos silviculturais (poda) foram realizados a cada três meses a partir da instalação do experimento. Após um ano de condução do experimento, foi realizada uma poda geral, isto é, foram podadas todas as mudas de todos os tratamentos (T1, T2, T3 e T4), com exceção do T0 (testemunha). Na avaliação do ano seguinte, as mudas foram submetidas à mesma seqüência de tratamentos realizados no ano anterior.

Semestralmente foram mensuradas as variáveis altura total e diâmetro de colo (medido à altura de $0,20 \mathrm{~cm}$ em relação ao solo) e, trimestralmente, o número de brotações podadas (incluindo gemas, ramos e galhos). Na última avaliação, foi medida a altura de bifurcação de todas as mudas.

Foram analisadas estatisticamente as variáveis incremento em altura total e em diâmetro (comparando-se as dimensões iniciais e finais das mudas após 24 meses de condução do experimento) e número de rebrotas. Inicialmente, as variâncias dos tratamentos foram avaliadas quanto a sua homogeneidade pelo teste de Bartlett. As variáveis cujas variâncias mostraram-se homogêneas tiveram as médias dos tratamentos testadas por meio do teste de F e comparadas pelo teste SNK (Student-NeumannKeul's Test) a 5\% de significância.

\section{RESULTADOS E DISCUSSÃO}

A maioria das mudas (92,5\%) de Allophylus edulis, com idade de cinco anos, após 24 meses de condução do experimento, ainda apresentava altura inferior à padrão para plantio nas ruas (Tabelas 1 e 2), necessitando de um maior tempo de permanência em viveiro.

Para a variável incremento em altura total houve diferença significativa $(\mathrm{p}>0,05)$ entre os tratamentos (Tabela 1). O tratamento T0 (sem aplicação de podas) diferiu estatisticamente do tratamento T3 (poda depois seis meses da instalação do experimento). Esses resultados indicam que a realização de podas sucessivas proporcionou maior crescimento em altura. Já para a variável incremento em diâmetro, não foi encontrada diferença significativa entre os tratamentos. Portanto, a aplicação de podas não alterou o crescimento em diâmetro.

Tabela 1. Avaliação do incremento em altura total e diâmetro de colo de Allophylus edulis. Table 1. Evaluation of total height and collar diameter growth of Allophylus edulis.

\begin{tabular}{lcccccc}
\hline \multirow{2}{*}{ Tratamentos } & \multicolumn{3}{c}{ Altura total (m) } & \multicolumn{3}{c}{ Diâmetro do colo (cm) } \\
\cline { 2 - 7 } & Inicial & Final & Incremento & Inicial & Final & Incremento \\
\hline T0 & 1,23 & 1,46 & $0,23 \quad \mathrm{~B}$ & 0,59 & 1,29 & $0,69 \mathrm{~A}$ \\
$\mathrm{~T} 1$ & 1,31 & 1,76 & $0,45 \mathrm{AB}$ & 0,77 & 1,40 & $0,63 \mathrm{~A}$ \\
$\mathrm{~T} 2$ & 1,26 & 1,78 & $0,52 \mathrm{AB}$ & 0,65 & 1,32 & $0,67 \mathrm{~A}$ \\
$\mathrm{~T} 3$ & 1,18 & 1,74 & $0,56 \mathrm{~A}$ & 0,66 & 1,28 & $0,63 \mathrm{~A}$ \\
T4 & 1,24 & 1,63 & $0,41 \mathrm{AB}$ & 0,71 & 1,23 & $0,52 \mathrm{~A}$ \\
\hline
\end{tabular}

Médias seguidas pela mesma letra maiúscula na vertical não diferem estatisticamente pelo teste SNK a 5\% de significância.

$\mathrm{Na}$ figura 1, observa-se que o incremento em altura, comparando-se as avaliações semestrais, foi menor no período outono/inverno $\left(1^{\mathrm{a}}\right.$ e $3^{\mathrm{a}}$ avaliações $)$ do que no período primavera/verão $\left(2^{\mathrm{a}}\right.$ e $4^{\mathrm{a}}$ avaliações). Algumas mudas inclusive apresentaram diminuição em altura devido à morte da gema apical, provavelmente pelas condições climáticas (baixas temperaturas e geadas). Almeida (2005) observou em mudas de Allophylus edulis a sensibilidade à geada, com algumas de suas folhas apresentando 
queimaduras decorrentes do frio, mesmo em local coberto (estufa), sendo que após alguns dias as folhas secaram e caíram, porém sem mortalidade das mudas.

Tabela 2. Distribuição da altura total e diâmetro de colo das mudas de Allophylus edulis em classes.

Table 2. Distribution of total height and collar diameter of Allophylus edulis in classes.

\begin{tabular}{lccc}
\hline Classes de altura (m) & \% mudas & $\begin{array}{c}\text { Classes de diâmetro } \\
(\mathbf{c m})\end{array}$ & \% mudas \\
\hline$<1,80$ & 67,50 & $<1,50$ & 87,50 \\
$1,80-2,00$ & 25,00 & $1,50-2,00$ & 12,50 \\
$>2,00$ & 7,50 & $>2,00$ & 0,00 \\
\hline
\end{tabular}

De acordo com Kramer e Kozlowski (1960), quando a gema apical bem definida é danificada ou removida, um dos ramos laterais localizados mais abaixo se adianta geralmente aos ramos vizinhos e forma um novo guia. No entanto, quando dois ou mais ramos laterais crescem num ritmo tão próximo que nenhum deles pode controlar o outro, isso dá origem a árvores com troncos bifurcados e copas em forma de candelabro.

Considerando a arquitetura de copa e o tipo de crescimento da espécie, constatou-se que essa espécie possui copa simpodial e crescimento do tipo plagiotrópico. Segundo Seitz (2003), em plantas com copa simpodial, após a morte do meristema apical desenvolvem-se meristemas laterais (gemas das axilas das folhas) que estavam dormentes. Dessa forma, o meristema apical tem vida limitada e conseqüentemente não ocorre o crescimento linear. $\mathrm{O}$ crescimento plagiotrópico caracteriza-se pelo crescimento dos meristemas horizontalmente ou obliquamente.

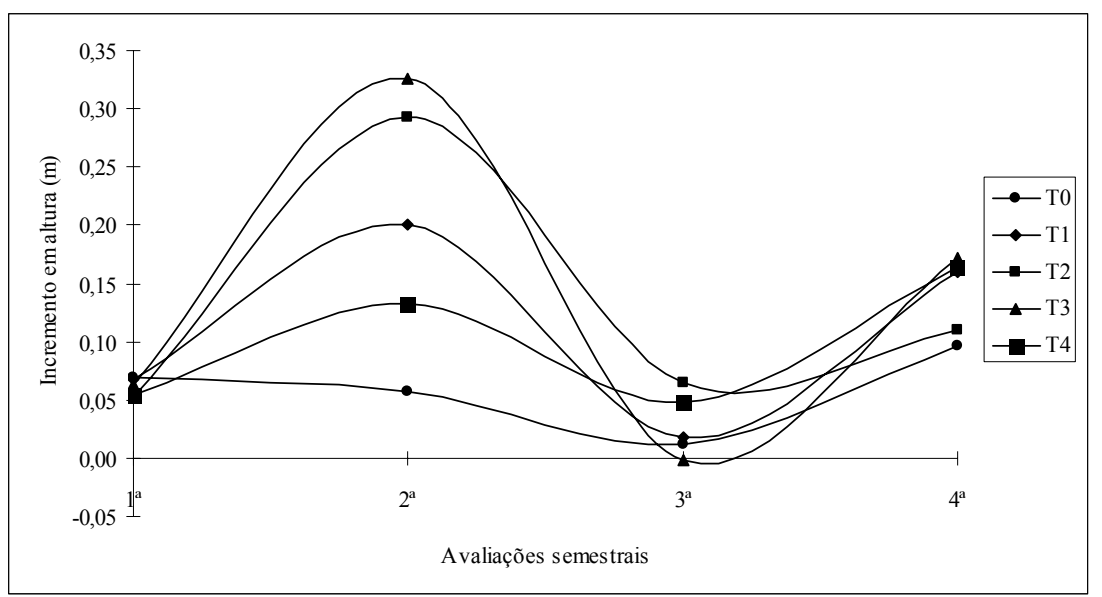

Figura 1. Avaliações semestrais do incremento em altura total de Allophylus edulis.

Figure 1. Semester evaluation of total height increment of Allophylus edulis.

$\mathrm{O}$ incremento em diâmetro nas avaliações semestrais (Figura 2) teve o mesmo comportamento que o incremento em altura, com maior aumento no período primavera-verão ( $2^{\mathrm{a}}$ avaliação). As condições de luz, umidade e temperatura no período de primavera-verão em Curitiba favoreceram os incrementos em diâmetro e altura, conforme a tendência observada por Kramer e Kozlowski (1960) e Soares e Batista (2004).

Quanto à altura de bifurcação, nas mudas em que a poda não foi aplicada (T0) a altura média de bifurcação foi de $0,22 \mathrm{~m}$, correspondendo a apenas $15,07 \%$ da altura total, diferindo estatisticamente da altura de 1,00 m estabelecida para os outros tratamentos. Isso indica que as mudas sem aplicação de tratamento silvicultural nunca teriam um fuste livre de ramificação a $1,80 \mathrm{~m}$, conforme Gonçalves et al. (2004) e Biondi e Althaus (2005).

$\mathrm{Na}$ obtenção de altura de esgalhamento adequada de Clitoria racemosa Sessé \& Moc. (Fabaceae), Biondi e Meunier (1987) observaram que, quando a poda foi efetuada ao menos uma vez durante a permanência da muda em viveiro, a altura de esgalhamento aumentou em $40 \%$ em mudas com quinze meses de idade. 


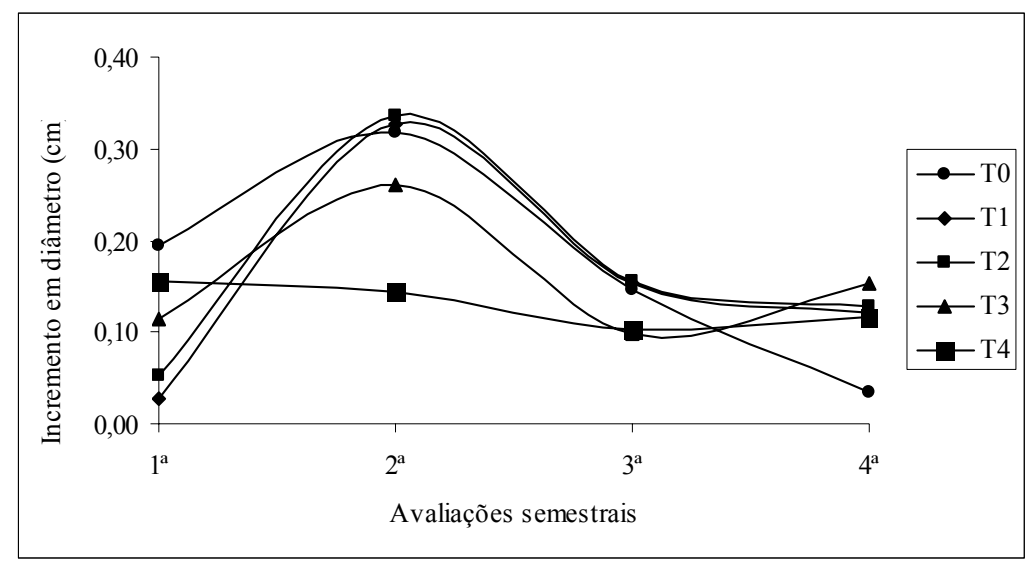

Figura 2. Avaliações semestrais do incremento em diâmetro do colo de Allophylus edulis.

Figure 2. Semester evaluation of collar diameter increment of Allophylus edulis.

$\mathrm{O}$ aspecto fuste livre de ramificações também pode estar associado à espécie. A. edulis é citada como espécie de fuste curto, de até $45 \mathrm{~cm}$ de diâmetro por Backes e Irgang (2004).

Após a realização das podas, observou-se a formação de brotações laterais em baixa altura. Verificou-se diferença estatisticamente significante entre o número total de brotações eliminadas nos tratamentos T1, T2, T3 e T4 e o número total de brotações existentes abaixo de 1,00 m de altura no tratamento T0 (Tabela 3). A emissão de brotações também pode ser uma característica da espécie. Almeida (2005) observou em mudas de Allophylus edulis, após 135 dias da emergência das plântulas, emissão de brotações laterais mesmo sem a perda da gema apical.

Comparando-se o número de brotações eliminadas nos tratamentos T1, T2, T3 e T4, na quinta e na nona avaliação, não houve diferença estatística entre elas (Tabela 3). Isso quer dizer que a freqüência de podas não diminuiu o número de rebrotas nas mudas dessa espécie. Assim, para a condução de mudas de Allophylus edulis, visando obter uma altura de bifurcação adequada $(1,80 \mathrm{~m})$, recomenda-se fazer a poda em intervalos de nove meses, a partir de 1,50 $\mathrm{m}$ de altura (no primeiro ano em viveiro de espera).

Tabela 3. Avaliação trimestral do número de brotações eliminadas.

Table 3. Trimester evaluation of recoppicing number eliminated.

\begin{tabular}{|c|c|c|c|c|c|c|c|c|c|c|}
\hline \multirow{2}{*}{ Tratamentos } & \multicolumn{9}{|c|}{ Avaliações trimestrais } & \multirow{2}{*}{ Soma } \\
\hline & $\mathbf{1}^{\mathrm{a}}$ & $2^{a}$ & $\mathbf{3}^{\mathrm{a}}$ & $4^{a}$ & $5^{a}$ & $6^{\mathrm{a}}$ & $7^{\mathrm{a}}$ & $\mathbf{8}^{\mathrm{a}}$ & $9^{a}$ & \\
\hline T0 ${ }^{1}$ & & & & & & & & & & $18,3 \mathrm{~B}$ \\
\hline $\mathrm{T} 1$ & 4,6 & 12,9 & 14,8 & 7,6 & $10,0 \mathrm{~A}$ & 0,8 & 0,0 & 1,6 & $5,1 \mathrm{~A}$ & $57,4 \mathrm{~A}$ \\
\hline $\mathrm{T} 2$ & & 9,2 & 9,1 & 10,0 & $5,5 \mathrm{~A}$ & 0,0 & 0,4 & 1,4 & $5,5 \mathrm{~A}$ & $41,1 \mathrm{~A}$ \\
\hline $\mathrm{T} 3$ & & & 17,8 & 15,1 & $12,5 \mathrm{~A}$ & & 1,0 & 2,2 & $3,2 \mathrm{~A}$ & $51,8 \mathrm{~A}$ \\
\hline $\mathrm{T} 4$ & & & & 22,9 & $7,50 \mathrm{~A}$ & & & 3,9 & $6,1 \mathrm{~A}$ & $40,4 \mathrm{~A}$ \\
\hline
\end{tabular}

${ }^{1}$ Número total de brotações existentes abaixo de $1,00 \mathrm{~m}$ de altura. Médias seguidas pela mesma letra maiúscula na vertical não diferem estatisticamente pelo teste SNK a 5\% de significância.

Para o tratamento T1, em que trimestralmente foram aplicadas podas sucessivas, observa-se uma diminuição no número de ramos podados na seqüência de podas (Figura 3). Observou-se também uma influência da época (estação do ano) na emissão de brotações. Entre a $4^{\mathrm{a}}$ e $5^{\mathrm{a}}$ e a $8^{\mathrm{a}}$ e $9^{\mathrm{a}}$ avaliações (correspondentes ao período primavera-verão) houve um aumento no número de brotações emitidas, enquanto que entre a $3^{\mathrm{a}}$ e $4^{\mathrm{a}}$ e a $6^{\mathrm{a}}$ e $7^{\mathrm{a}}$ avaliações (correspondentes a inverno-primavera e outonoinverno) houve uma diminuição no número de brotações. Na sétima avaliação não houve rebrota (zero brotações), conforme também observado na tabela 3.

Isso indica que o período primavera-verão é a melhor época para a eliminação dos brotos, evitando que eles formem ramificações vigorosas que eventualmente poderão comprometer tanto a altura como o diâmetro. De acordo com Kramer e Kozlowski (1960), a não-remoção dos ramos vivos do caule pode consumir, na respiração, os hidratos de carbono que são produzidos na fotossíntese, prejudicando 
assim o crescimento. Portanto, a remoção dos ramos, além de colaborar com o crescimento, ajuda a produzir uma muda com maior altura de bifurcação, isto é, caule livre de ramificações até o início do esgalhamento que forma a copa.

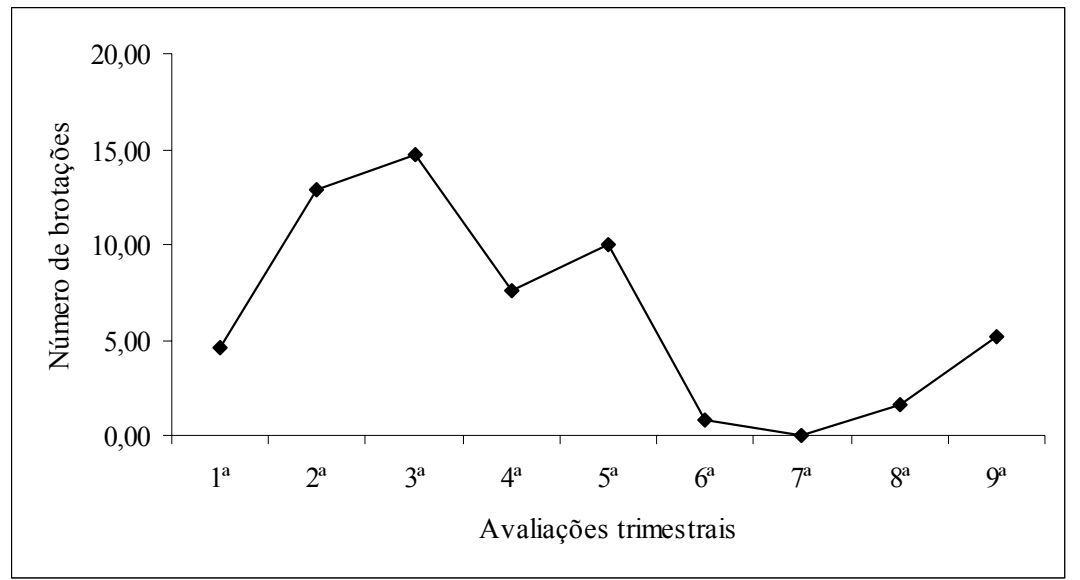

Figura 3. Avaliação trimestral do número de brotações eliminadas no tratamento T1.

Figure 3. Trimester evaluation of recoppicing number eliminated in the treatment T1.

\section{CONCLUSÕES}

Em face dos resultados obtidos em relação à produção de mudas de Allophylus edulis, conclui-se que:

- A aplicação das podas influenciou o incremento em altura total e altura de bifurcação, mas não alterou o incremento em diâmetro.

- A freqüência de podas não diminuiu o número de rebrotas nas mudas. Recomenda-se, portanto, podas de condução a cada nove meses em mudas com altura superior a $1,50 \mathrm{~m}$, a partir do primeiro ano, em viveiro de espera.

- A melhor época para aplicação de podas nas mudas é no final da primavera ou verão, para evitar que as brotações formem ramos vigorosos e diminuam a altura de bifurcação.

- Em virtude da baixa percentagem de mudas com altura igual ou superior a 1,80 m, é necessário que se prossiga este experimento por um período de tempo maior, para se conhecer o tempo necessário para a produção de mudas dessa espécie em viveiro de espera.

\section{REFERÊNCIAS}

ALMEIDA, L. S. Avaliação morfológica de mudas de Allophylus edulis (A. St.-Hil., Cambess. \& A. Juss.) Radl. (vacum) e Schinus terebinthifolius Raddi (aroeira) produzidas em diferentes substratos. 96 f. Dissertação (Mestrado em Engenharia Florestal) - Setor de Ciências Agrárias, Universidade Federal do Paraná, Curitiba, 2005.

BACKES, P.; IRGANG, B. Mata Atlântica: as árvores e a paisagem. Porto Alegre: Paisagem do Sul, 2004. p. 351.

BIONDI, D. Tratamentos silviculturais em árvores de rua. In: Encontro Nacional Sobre Arborização Urbana, 2., 1987, Maringá. Anais... Maringá: SBAU, 1987. p. 43 - 47.

BIONDI, D.; ALTHAUS. M. Árvores de rua de Curitiba: cultivo e manejo. Curitiba: FUPEF, 2005. 182 p.

BIONDI, D.; MEUNIER, I. Obtenção de altura de esgalhamento adequada de Clitoria racemosa para uso na arborização de ruas. In: Encontro Nacional Sobre Arborização Urbana, 2., 1987, Maringá. Anais... Maringá: SBAU, 1987. p. 144 - 147. 
CARVALHO, J.; SOUZA, S. G. A.; RODERJAN, C. V.; MARQUES, M. C. M. Estrutura de uma população de Allophylus edulis (St. Hill.) Radlk. em floresta ciliar do rio Barigui, Araucária - PR. Disponível em: <http://www.adaltech.com.br/evento/museugoeldi/resumoshtm/resumos/R0451-1.htm> Acesso em: 12 agosto 2004.

CEMIG. Política interna da CEMIG. Poda de árvores e arborização urbana: diretrizes para a adequação ambiental. Belo Horizonte, 2000.

DOMINGUES, Z. H. Produção de mudas para arborização de ruas. In: Encontro Nacional Sobre Arborização Urbana, 2., 1987, Maringá. Anais... Maringá: SBAU, 1987. p. 09 - 19.

Gimenez, A. M.; MOGliA, J. G. Árboles del Chaco Argentino: guía para el reconocimiento dendrológico. Santiago del Estero: El Liberal S. R. L., 2003. p. 215.

GONÇALVES, E. O.; PAIVA, H. N.; GONÇALVES, W.; JACOVINE, L. A. G. Avaliação qualitativa de mudas destinadas à arborização urbana no estado de Minas Gerais. Revista Árvore, Viçosa, MG, v. 28, n. 4, p. 479 - 486, 2004.

HARRIS, R. W. Arboriculture: integrated management of landscape trees, shrubs and vines. 2. ed. New Jersey: Prentice Hall, 1992. 674 p.

KRAMER, P. J.; KOZLOWSKI, T. Fisiologia das árvores. Lisboa: Fundação Calouste Gulbenkian, 1960. 745 p.

LORENZI, H. Árvores brasileiras: manual de identificação e cultivo de plantas arbóreas nativas do Brasil. Nova Odessa: Plantarum, 1992. p. 315.

MARCHIORI, J. N. C. Elementos de dendrologia. Santa Maria: UFSM, 1995. 163 p.

MEDEIROS, A. C.; ABREU, D. C. A. Comportamento germinativo de sementes de vacum (Allophylus edulis) em diferentes estágios de maturação. In: Congresso Brasileiro de Sementes, 13., 2003, Gramado. Anais... Gramado: Informativo ABRATES, v. 13, n. 3, 2003. p. 384.

PAIVA, H. N.; GONÇALVES, W. Produção de mudas. Viçosa: Aprenda Fácil, 2001. p. 107 - 112.

REITZ, P. Sapindáceas. In: REITZ, P. Flora Ilustrada Catarinense. Itajaí: Herbário Barbosa Rodrigues, 1980. p. 108 - 112.

RODERJAN, C. V.; GALVÃO, F.; KUNIYOSHI, Y. S.; HATSCHBACH, G. G. As unidades fitogeográficas do estado do Paraná. Ciência \& Ambiente, Santa Maria, n. 24, p. 78 - 118, 2002.

SANCHONETE, M. C. C. Frutíferas nativas úteis à fauna na arborização urbana. Porto Alegre: SAGRA, 1989. $306 \mathrm{p}$.

SANTIAGO, A. C. Arborização das cidades. Boletim Técnico CATI, Campinas, n. 90, 1980.

SEITZ, R. A. A poda de árvores urbanas. Curitiba: FUPEF, 2003. 40 p. (Série Técnica, n. 19).

SOARES, R. V.; BATISTA, A. C. Meteorologia e climatologia florestal. Curitiba: FUPEF, 2004. 195 p. 